\section{Floral Development and Bolting of Spinach as Affected by Photoperiod and Integrated Photosynthetic Photon Flux During Transplant Production}

\author{
Changhoo Chun ${ }^{1}$, Machiko Tominaga ${ }^{2}$, and Toyoki Kozai ${ }^{3}$ \\ Department of Bioproduction Science, Faculty of Horticulture, Chiba \\ University, Matsudo, Chiba 271-8510, Japan
}

\section{Additional index words. closed system, fluorescent lamps, hydroponics, IPPF, Spinacia oleracea}

\begin{abstract}
We recently showed that spinach (Spinacia oleracea L.) $_{\text {.) }}$ transplants produced under a short photoperiod and low air temperature were characterized by a delay of bolting and short flower-stalk length at harvest (Chun et al., 2000a). The present study was conducted to determine whether these changes are caused by the short photoperiod itself or by the lower integrated photosynthetic photon flux $(I P P F)$. Shoot and root dry weights of transplants increased significantly with increasing $I P P F$, but were not affected by a change in the photoperiod. However, the floral development indices of transplants were significantly greater under a 16- than under a 10- or 13-hours/day photoperiod, but were not affected by a change in $I P P F$. The percentage of bolted plants 3 days after transplanting (DAT) increased significantly with increasing photoperiod (from $0 \%$ at 10 hours/day to more than $85 \%$ at 16 hours/day). Flower-stalk length increased with increasing photoperiod (e.g., at $14 \mathrm{DAT}$, from $15 \mathrm{~mm}$ at the shorter photoperiods to $80 \mathrm{~mm}$ at 16 hours/day), but was not affected by a change in IPPF. These results show that the delay of bolting that occurs when the photoperiod is reduced during transplant production is due to the delay of floral development and not to retarded vegetative growth as a result of reduced $I P P F$.
\end{abstract}

A long photoperiod causes spinach plants to bolt and flower (Garner and Allard, 1920; Hartmann et al., 1988; Kim et al., 2000), and bolted plants lose their market value (Kagawa, 1997). We recently proposed a method for producing spinach transplants in a closed system (Chun et al., 2000a). In this method, the photoperiod is shortened and air temperature is lowered, resulting in short flower stalks at harvest, even when the transplants are subsequently cultured under long-day and high air temperature conditions.

Increasing the photoperiod but maintaining a constant photosynthetic photon flux $(P P F)$ resulted in increased vegetative growth of transplants, and promoted floral development and elongation of flower stalks (Chun et al., 2000a; Kim et al. 2000). However, it was not clear from these studies whether the inhibition of bolting and flower-stalk elongation that occurred with a shorter photoperiod was

Received for publication 5 July 2000. Accepted for publication 17 Nov. 2000. We thank Hyeon-Hye Kim for her technical advice on observing floral development, and Katuyoshi Okabe and Junya Fuse for their technical support. The cost of publishing this paper was defrayed in part by the payment of page charges. Under postal regulations, this paper therefore must be hereby marked advertisement solely to indicate this fact.

${ }^{1}$ Associate Professor. E-mail address: changhoo@ midori.h.chiba-u.ac.jp.

${ }^{2}$ Undergraduate Research Associate. Current address: Planet Co., Ltd., Tokyo 150-0001, Japan. ${ }^{3}$ Professor. due to delayed floral development or retarded vegetative growth as a result of the decreased integrated photosynthetic photon flux (IPPF). The IPPF $\left(\mathrm{mol} \cdot \mathrm{m}^{-2}\right)$ is the product of photope$\operatorname{riod}(\mathrm{h} / \mathrm{d}), P P F\left(\mathrm{~mol} \cdot \mathrm{m}^{-2} \cdot \mathrm{s}^{-1}\right)$, and production period (d). Vegetative growth (e.g., the increase in dry weight) depends on the IPPF (Kitaya et al., 1998), and vegetative growth affects the floral development of quantitative long/short-day plants (Thomas and Vince-Prue, 1997). However, few studies have examined the effects of $I P P F$ on floral development of qualitative long/short-day plants, including spinach.

To clarify the effects of the photoperiod during transplant production on bolting of spinach, we investigated floral development in transplants grown under different photoperiods but the same $I P P F$, and under the same photoperiod but different IPPFs. In addition, bolting in these plants during subsequent culture was also investigated.

\section{Materials and Methods}

Transplantproduction. In the present study, S. oleracea L., cv. Dimple (Sakata Seed Co., Yokohama, Japan), was used. This cultivar is a semi-savoy type and its critical daylength for bolting initiation is between 13 and $15 \mathrm{~h} / \mathrm{d}$ (Chun et al, 2000b). Five seeds were sown in each cell (20 $\mathrm{mm}$ in diameter) of transplant production trays (48 cells per tray, $300 \times 200$ $\times 40(\mathrm{H}) \mathrm{mm}$; Taiyo Kogyo Co., Tokyo) that had been filled with $3 \mathrm{~g}$ (dry weight) of granules of rock-wool (Nichias Co., Tokyo). The trays with seeds were wrapped with opaque plastic sheets and placed in a walk-in growth chamber for $3 \mathrm{~d}$ for germination. During this period, the air temperature was maintained at $20 \pm 1{ }^{\circ} \mathrm{C}$ and the relative humidity at $70 \% \pm$ $5 \%$.

The trays with germinated seeds were moved to three growth chambers (Koitotron 3HN-35MLA; Koito Industries, Yokohama, Japan) and cultured for $11 \mathrm{~d}$. Each chamber $[100 \times 100 \times 150(\mathrm{H}) \mathrm{cm}]$ had a microwavepowered lamp as described by Kozai et al. (1995). The lamp (Solar 1000 ${ }^{\mathrm{TM}}$ Lighting System SAB; Fusion Lighting, Rockville, Md.) was used as the sole source of light. The lamp was essentially a point lighting source, so $P P F$ varied with distance from the lamp. To achieve a uniform $P P F$ at the surface of the tray, a screen frame was placed $50 \mathrm{~cm}$ from the lamp and circular shading material made of white plastic net (mesh size $0.8 \mathrm{~mm}, \mathrm{GN}-2300$; Nihon Wide Cloth Co., Osaka, Japan) was placed near the center of the screen. The photo-/dark periods in the three chambers were set at 10/ $14,13 / 11$, and $16 / 8 \mathrm{~h} / \mathrm{d}$, respectively. In each chamber, the $P P F$ at the surface of the trays was set at two different values (Table 1) by placing additional semicircular shading materials on one half of the screen. The number of pieces of shading material was chosen so that, although there were six different treatments, there were only three different IPPFs $(\approx 80$, 125 , and $200 \mathrm{~mol} \cdot \mathrm{m}^{-2}$; Table 1 ).

During the transplant production period, the air temperature and relative humidity $(\mathrm{RH})$ in each chamber were maintained at $20 \pm 1{ }^{\circ} \mathrm{C}$ and $70 \% \pm 5 \% \mathrm{RH}$. The $\mathrm{CO}_{2}$ concentration during the photo- and dark periods was maintained at 700 and $350 \mu \mathrm{mol} \cdot \mathrm{mol}^{-1}$, respectively. Trays were irrigated once a day with diluted commercial nutrient solution (High Tempo; Sumitomo Chemical Co., Tokyo) containing $\left(\mathrm{mmol} \cdot \mathrm{L}^{-1}\right): 12.0 \mathrm{NO}_{3}-\mathrm{N}, 0.8 \mathrm{NH}_{4}-\mathrm{N}$, 30.6 P, 7.3 K, 10.2 Ca, and 4.2 Mg. The $\mathrm{pH}$ and electrical conductivity (EC) of the nutrient solution were 6.0 and $140 \mathrm{mS} \cdot \mathrm{m}^{-1}$, respectively. Shoot and root dry weights of 16 transplants from each replication were measured $14 \mathrm{~d}$ after sowing (DAS).

At 14 DAS, meristems of transplants were viewed and photographed using a digital microscope (VH-6300; Keyence Co., Osaka, Japan). The floral development of an apical meristem can be divided into four stages, according to Eguchi and Ichikawa (1940) and Kim et al. (2000). When a transplant had a flat shoot apex with only subtending leaf primordia, it was characterized as being in the vegetative stage (no floral differentiation) and was given a score of 0 . When the apex formed a hemispherically shaped dome, the transplant was classified as being in the flower cluster initiation stage and was given a score of 1 . If the diameter of the dome was significantly larger than that at the flower cluster initiation stage, it was classified as being in the flower cluster differentiation stage and was given a score of 2 . And when many flower clusters and bracts had formed, the apex was classified as being in the flower cluster formation stage and was given a score of 3 . Five transplants from 
Table 1. Photoperiod, $P P F$, and $I P P F$ of each treatment during an 11-d transplant production.

\begin{tabular}{lcccc}
\hline $\begin{array}{l}\text { Chamber } \\
\text { no. }\end{array}$ & $\begin{array}{c}\text { Photoperiod } \\
(\mathrm{h} / \mathrm{d})\end{array}$ & $\begin{array}{c}P P F^{\mathrm{z}} \\
\left(\mu \mathrm{mol} \cdot \mathrm{m}^{-2} \cdot \mathrm{s}^{-1}\right)\end{array}$ & $\begin{array}{c}I P P F^{\mathrm{y}} \\
\left(\mathrm{mol} \cdot \mathrm{m}^{-2}\right)\end{array}$ & $\begin{array}{c}\text { Treatment } \\
\text { code }\end{array}$ \\
\hline 1 & 10 & $200 \pm 5$ & 81.2 & $\mathrm{P} 10, \mathrm{I} 80$ \\
& & $320 \pm 12$ & 126.7 & $\mathrm{P} 10, \mathrm{I} 125$ \\
2 & 13 & $155 \pm 10$ & 80.0 & $\mathrm{P} 13, \mathrm{I} 80$ \\
3 & & $390 \pm 40$ & 200.8 & $\mathrm{P} 13, \mathrm{I} 200$ \\
& 16 & $200 \pm 6$ & 120.4 & $\mathrm{P} 16, \mathrm{I125}$ \\
& & $320 \pm 26$ & 202.7 & $\mathrm{P} 16, \mathrm{I} 200$ \\
\hline
\end{tabular}

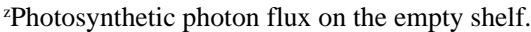

${ }^{y} I P P F=P P F \times$ photoperiod $\times 11$ (number of days for transplant production). each treatment were destructively sampled to determine the stage of floral development.

Culture after transplanting. At $14 \mathrm{DAS}$, the plants were transplanted to four modified nutrient film technique (NFT) (Cooper, 1973), hydroponic systems installed in a walk-in growth chamber and were grown for 14 more days. Cool-white fluorescent lamps (FPL55EX-N; MatsushitaElectronics Co., Osaka, Japan) were used as an artificial light source and the average $P P F$ on the planting panels $(26 \mathrm{~cm}$ below the lamps) was $320 \pm 20 \mu \mathrm{mol} \cdot \mathrm{m}^{-2} \cdot \mathrm{s}^{-1}$. The photoand dark periods in the NFT systems were 16 and $8 \mathrm{~h} / \mathrm{d}$, respectively. The plants were placed on planting panels (Taiyo Kogyo Co., Tokyo) at a density of 63 cells $/ \mathrm{m}^{2}$. In the NFT system, the diluted commercial nutrient solution (High Tempo; Sumitomo Chemical Co., Tokyo) was continuously circulated between the nutrient tank and the culture beds. The EC of the solution was $280 \mathrm{mS} \cdot \mathrm{m}^{-1}$. The average air temperatures during the photo- and dark periods were 33 and $31{ }^{\circ} \mathrm{C}$, respectively, and the average solution temperature was $22^{\circ} \mathrm{C}$.

For 20 plants from each replication, the percentage of bolted plants was observed throughout the culturing period [ 0 to $14 \mathrm{~d}$ after transplanting (DAT)] and flower-stalk length was measured 5, 10, and 14 DAT. At harvest (14 DAT), shoot and root dry weights and leaf number of 14 plants sampled from each replication were measured.

A completely randomized design was used with two replications. A tray for transplant production represented a replication and an Duncan's multiple range test at $P \leq 0.05$ were used to compare means in each treatment.

\section{Results}

At the end of the transplant-production period(14DAS), shoot and root dry weights of the transplants had increased significantly with increasing IPPF (Fig. 1), but prolonging the photoperiod did not increase dry weight within $I P P F$ treatments. The floral development indices of transplants grown under a 16-h photoperiod were significantly greater than those under the 10- or the 13-h photoperiod, while no difference was found among the 10- and the 13-h photoperiod treatments (Fig. 1). Furthermore, transplants grown under the same photoperiod showed the same floral development index regardless of the $I P P F$.

Of the plants grown under a $16-\mathrm{h}$ photoperiod, $>85 \%$ had bolted 3 DAT, while $15 \%$ to analysis of variance (ANOVA) test and
$40 \%$ of the plants in the $13-\mathrm{h}$ photoperiod treatments and none of the plants in the 10-h photoperiod treatments had bolted at this time (Fig. 2A). The percentage of bolted plants in the 16-h photoperiod treatments reached $100 \%$ 7 DAT. However, the percentage of bolted plants 14 DAT did not differ between the 13and the 16-h photoperiod treatments. Under that bolted after 11 DAT was greater at the higher IPPF. The flower-stalk lengths of plants 5 DAT in the 16-h photoperiod treatments were $\approx 10 \mathrm{~mm}$, while those in the other treatments were $0 \mathrm{~mm}$ (Fig. 2B); at harvest, they were $\approx 80 \mathrm{~mm}$ under the 16 -h photoperiods, but only $\approx 15 \mathrm{~mm}$ in the other treatments. The $I P P F$ did not affect flower-stalk length within photoperiods. There were no significant differences in shoot and root dry weights among treatments at harvest (data not shown), but leaf number was greater in the 16 -h photoperiod treatments (Fig. 3).

\section{Discussion}

Growth and floral development at transplanting. Several studies have shown a rela10-h photoperiods, the percentage of plants tion between $P P F$ or $I P P F$ and plant growth Ikeda et al. (1988) and Knight and Mitchell (1988) reported that increasing PPF promoted vegetative growth of lettuce (Lactuca sativa L.). Since only one photoperiod was used in these studies, it can be concluded that vegetative growth is also dependent on $P P F$. Kitaya et al. (1998) demonstrated that the dry weight of lettuce increased with increasing daily $I P P F$. In that study, daily $I P P F$ values ranging from 5.8 to $25.9 \mathrm{~mol} \cdot \mathrm{m}^{-2} \cdot \mathrm{d}^{-1}$ were achieved by using different combinations of photoperiods (from 16 to $24 \mathrm{~h} / \mathrm{d}$ ) and PPFs (from 100 to $300 \mu \mathrm{mol} \cdot \mathrm{m}^{-2} \cdot \mathrm{s}^{-1}$ ). Chun et al. $(2000 \mathrm{~b})$ reported that increasing the photoperiod from 11 to $15 \mathrm{~h} / \mathrm{d}$ with $P P F$ of 310 $\mu \mathrm{mol} \cdot \mathrm{m}^{-2} \cdot \mathrm{s}^{-1}$ during transplant production promoted bolting and flower-stalk elongation of 'Dimple' spinach plants that were subsequently cultured under long-day conditions.

As shown in Fig. 1, vegetative growth of spinach transplants (on a dry weight basis) was dependent on the $I P P F$ rather than on the photoperiod itself. These transplants, which were grown under different photoperiods but which exhibited the same vegetative growth, were used for examining the effects of the photoperiod and IPPF during transplant production on the bolting characteristics. By using such plants, the effects of $I P P F$ on vegetative growth could be avoided.

Spinach has been classified as an absolute or a qualitative long-day plant (Boswell, 1935; Garner and Allard, 1920; Kagawa, 1997; Metzger and Zeevaart, 1980; Salisbury and Ross, 1978; Vince-Prue, 1975). However, Eguchi and Ichikawa (1940) found that spinach differentiated reproductive structures between 15 and 30DAS under natural conditions throughout the year, and Kim et al. (2000) reported that the differentiation occurred ear-

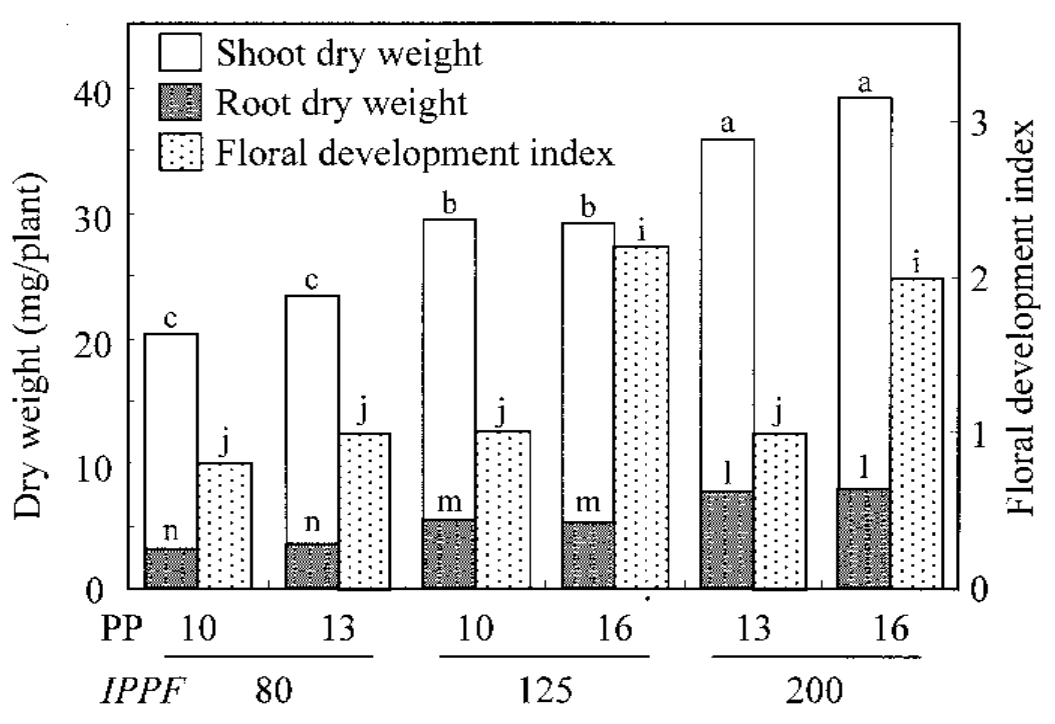

Fig. 1. Shoot and root dry weights and floral development indices of 'Dimple' spinach transplants $14 \mathrm{~d}$ after sowing as affected by photoperiod (PP) and integrated $P P F(I P P F)\left(\mathrm{mol} \cdot \mathrm{m}^{-2}\right)$ over an 11-d transplant production period. The floral development of a terminal apical meristem was divided into four stages according to Kim et al. (2000) and scored from 0 to 3, where $0=$ no floral differentiation, $1=$ flower cluster initiation stage, 2 = flower cluster differentiation stage, and $3=$ flower cluster formation stage Mean separation among fresh $(a, b, c)$ and dry weights $(1, m, n)$, and floral development index $(i, j)$ values by Duncan's multiple range test, $P \leq 0.05$. 


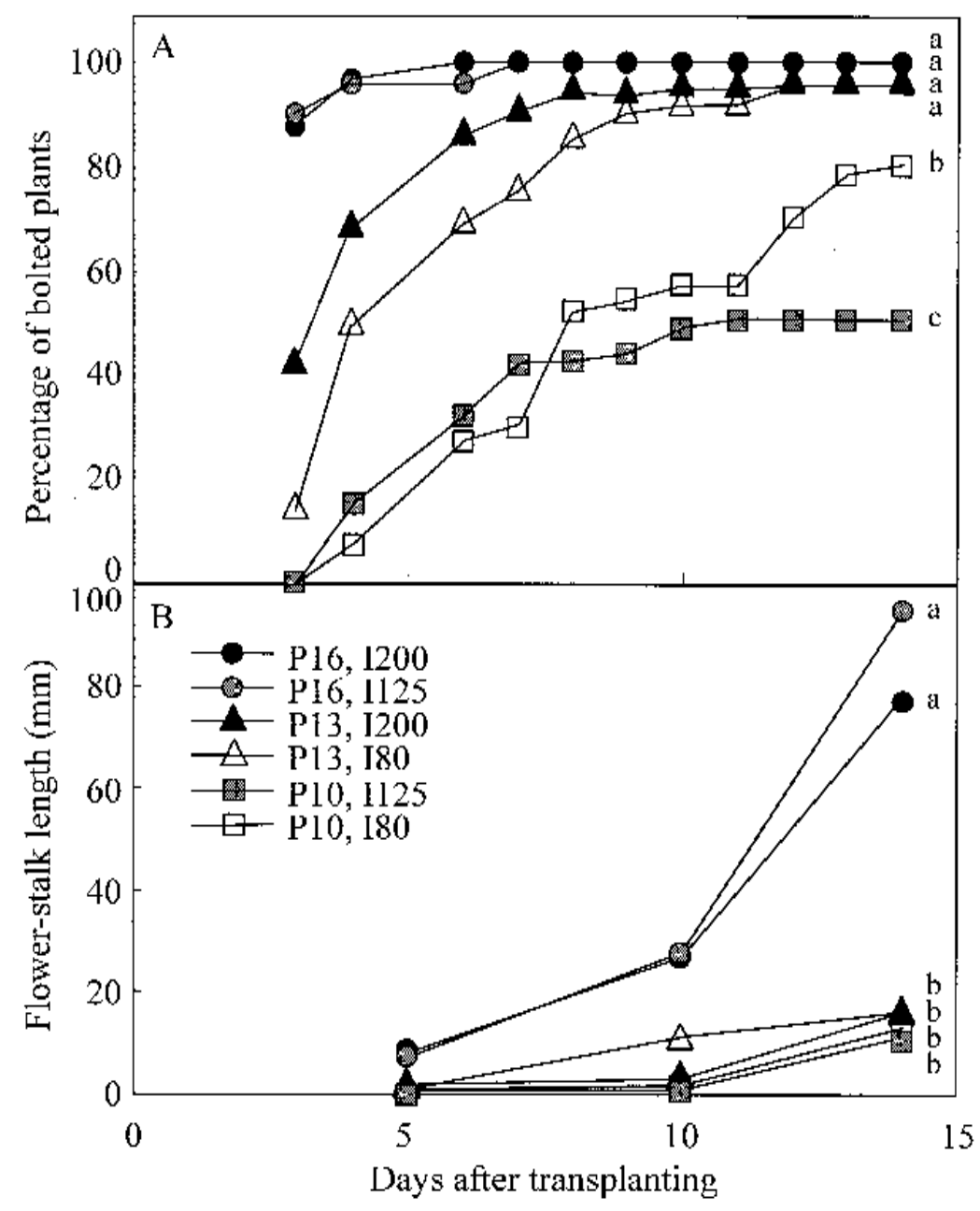

Fig. 2. (A) Time course of bolting percentage and (B) flower-stalk elongation of 'Dimple' spinach subsequently cultured under a 16-h photoperiod, as affected by photoperiod (PP) and integrated $P P F$ $(I P P F)$ over an 11-d transplant production period. Mean separation at 14 DAT by Duncan's multiple range test, $P \leq 0.05$. Treatment codes: $\mathrm{P}=$ photoperiod $(\mathrm{h}) ; \mathrm{I}=I P P F\left(\mathrm{~mol} \cdot \mathrm{m}^{-2}\right)$.

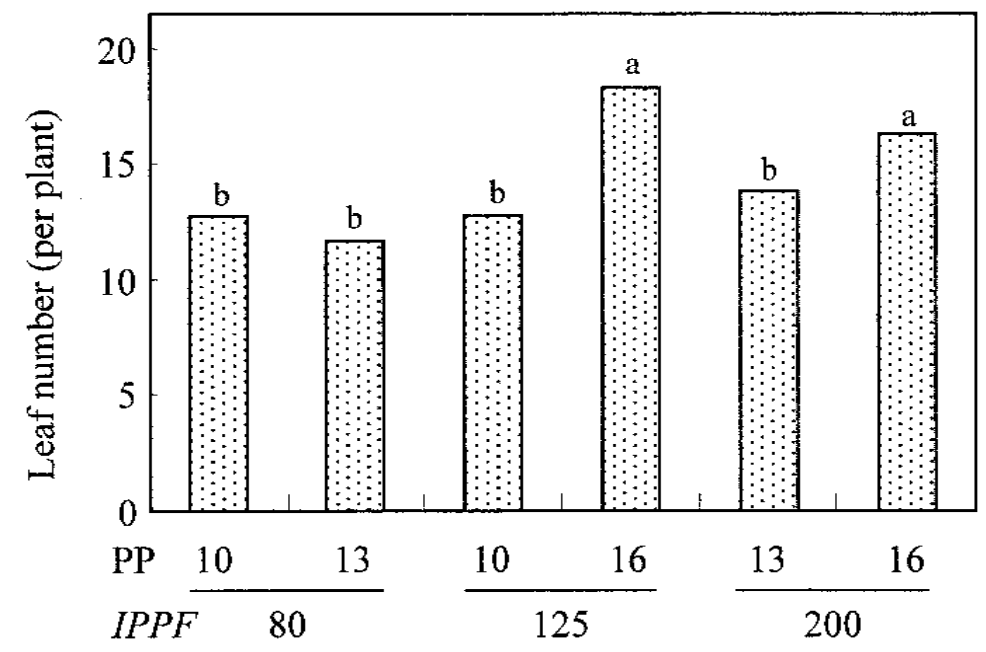

Fig. 3. Leaf number of 'Dimple' spinach subsequently cultured for $14 \mathrm{~d}$ under a 16-h photoperiod as affected by photoperiod (PP) and $I P P F$ over an 11-d transplant production period. Mean separation by Duncan's multiple range test, $P \leq 0.05$. lier than 17 DAS under artificial lighting. In agreement with Eguchi and Ichikawa (1940) and Kim et al. (2000), we found that the transformation from the vegetative to the reproductive state occurred in all photoperiods (Fig. 1). However, our results on the timing of development of reproductive structures could not be directly compared with those of Eguchi and Ichikawa (1940) and Kim et al. (2000) because of differences in lighting sources and other environmental factors. We found that floral development progressed further under $16-h$ photoperiods than in the other treatments, and that the floral development indices were not affected by IPPF when photoperiod was constant (Fig. 1). These findings suggest that the development of differentiated reproductive structures was not dependent on vegetative growth, but on the photoperiod, although floral initiation itself occurred regardless of the photoperiod and IPPF.

Growth and bolting at harvest. The photoperiod during transplant production had a significant effect on the percentage of bolted plants (Fig. 2A) and on flower-stalk length (Fig. 2B) of 'Dimple' spinach subsequently grown under a 16-h photoperiod. Chun et al. (2000b) reported that the critical day length for bolting of 'Dimple' spinach was longer than $13 \mathrm{~h}$ and shorter than $15 \mathrm{~h}$. The percentage of bolted plants 3 DAT was significantly higher under 16-h photoperiods than in the other treatments. This raises the possibility that the bolting of the plants in the 16 -h photoperiod treatments was initiated during the 11-d transplant-production period. However, for the plants in the 10- and the 13-h photoperiod treatments, bolting might have been initiated after these plants were transplanted and grown under a $16-h$ photoperiod. Even though no difference was found in the flower development indices between the 10- and the 13-h photoperiods (Fig. 1), the timing of development of reproductive structures in the 13-h photoperiods (earlier than 3 DAT) differed from that in the 10-h photoperiod (between 3 and 4 DAT). Kim et al. (2000) reported that flower-bud development of 'Dimple' spinach was accelerated by increasing the photoperiod from 8 to $16 \mathrm{~h}$. However, more precise anatomical observations of the reproductive structures and more precise measurement of the percentage of bolted plants at transplanting ( 0 DAT) are necessary to clarify this matter.

The photoperiod during transplant production had distinct effects on the flower-stalk length (Fig. 2B) and on leaf number (Fig. 3B) at harvest, but no effect on dry weight. (Fig. $3 \mathrm{~A})$. However, the $I P P F$ had no clear effect on bolting percentage, flower-stalk length, or leaf number. Based on this effect of photoperiod on bolting of spinach, Chun et al. (2000a) proposed that spinach transplants with delayed bolting could be produced by growing them under a short photoperiod using artificial lighting.

These present findings indicate that a longer photoperiod during transplant production enhances floral development and increases percentage bolting and flower-stalk length, but that the IPPF during transplant production 
does not affect flowering characteristics. In this study, we were unable to determine why the percentage of bolted plants increased more rapidly after $11 \mathrm{DAT}$ when $I P P F$ was raised from 125 to $180 \mathrm{~mol} \cdot \mathrm{m}^{-2}$ on a 10 -h photoperiod (Fig. 2A).

The present results indicate that the delay of bolting that occurs with shortening the photoperiod during transplant production is due to delayed floral development and not to retardation of vegetative growth as a result of the decreased $I P P F$.

\section{Literature Cited}

Boswell, R. 1935. Studies of the temperature, day length and development interrelations of spinach varieties in the field. Proc. Amer. Soc. Hort. Sci. 32:549-557.

Chun, C., T. Kozai, C. Kubota, and K. Okabe. 2000a. Manipulation of bolting and flowering in a spinach (Spinacia oleracea L.) transplant production system using artificial light. Acta Hort. 515:201-206.

Chun, C., A. Watanabe, H.-H. Kim, T. Kozai, and J. Fuse. 2000b. Bolting and growth of spinach
(Spinacia oleracea $\mathrm{L}$.) can be altered by using artificial lighting to modify the photoperiod during transplant production. HortScience 35:624-626.

Cooper, A.J. 1973. Rapid turn-round is possible with experimental nutrient film technique. The Grower 79:1048-1051.

Eguchi, T. and H. Ichikawa. 1940. Studies on the flower bud development and bolting of spinach (in Japanese). J. Jpn. Soc. Hort. Sci. 11:13-56.

Garner, W.W. and H.A. Allard, 1920. Effect of the relative length of day and night and the factors of the environment upon growth and reproduction in plants. J. Agr. Res. 18:553-606.

Hartmann, H.T., A.M. Kofranek, V.E. Rubatzky, and W.J. Flocker. 1988. Plant science. PrenticeHall, Englewood Cliffs, N.J.

Ikeda, A., S. Nakayama, Y. Kiaya, and K. Yabuki. 1988. Effects of photoperiod, $\mathrm{CO}_{2}$ concentration, and light intensity on growth and net photosynthetic rates of lettuce and turnip. Acta Hort. 229:273-282.

Kagawa, A. 1997. Physiology in cultivation of highquality spinach (in Japanese). Ishizue Publ., Tokyo.

Kim, H-.H., C. Chun, T. Kozai, and J. Fuse. 2000. The potential use of photoperiod during trans- plant production under artificial lighting condition on floral development and bolting, using Spinacia oleracea L. as a model. HortScience 35:43-45.

Kitaya, Y., G. Niu, T. Kozai, and M. Ohashi. 1998. Photosynthetic photon flux, photoperiod, and $\mathrm{CO}_{2}$ concentration affect growth and morphology of lettuce plug transplants. HortScience 33:988-991.

Knight, S.L. and C.A. Mitchell. 1988. Effects of $\mathrm{CO}_{2}$ and photosynthetic photon flux on yield, gas exchange and growth rate of Lactuta sativa $\mathrm{L}$. 'Waldmann's Green'. J. Expt. Bot. 39:317-328.

Kozai, T., Y. Kitaya, and Y.S. Oh. 1995. Microwavepowered lamp as a high intensity light source for plant growth. Acta Hort. 399:107-112.

Metzger, J.D. and J.A.D. Zeevaart. 1980. Effect of photoperiod on the levels of endogenous gibberellins in spinach as measured by combined gas chromatography-selected ion current monitoring. Plant Physiol. 66:844-846.

Salisbury, F.B. and C. Ross. 1978. Plant physiology, 2nd ed. Wadsworth, Belmont, Calif.

Thomas, B. and D. Vince-Prue. 1997. Photoperiodism in plants, 2nd ed. Academic, San Diego.

Vince-Prue, D. 1975. Photoperiodism in plants. McGraw-Hill, London. 